\title{
System Construction Strategy of Campus Broadcast and TV Network under the Background of Triple Play
}

\author{
Kai Liür, a \\ ${ }^{1}$ Wuhan Textile University, Wuhan, Hubei Province, China, 430200 \\ ${ }^{a}$ email
}

Keywords: Construction Strategy, Broadcast and TV Network, Trip Play

\begin{abstract}
With the gradual promoting policy of the triple play, Internet TV - this emerging network television in the future is bound to occupy a place in the media, and traditional TV has a certain impact. Therefore, based on the triple play, this paper describes the construction strategy campus radio and television networks.
\end{abstract}

\section{Introduction}

The State Council attaches great importance to the work of triple play, triple play will be integrated into national development strategies. 2010 the State Council as well as the overall program triple play pilot program, specifically the first triple play in 12 pilot areas list, which includes the city of Xiamen. In August 2013, the State Council is executive meeting to discuss the "Opinions on Promoting information consumption to expand domestic demand," to speed up the evolution of the information infrastructure upgrading, and comprehensively promote the triple play. To promote two-way radio and television and telecommunications services to penetrate into, on a pilot basis and gradually across the country. Expedite the implementation of terrestrial digital television coverage and high-definition interactive television network construction facilities and speed up the broadcast television analog to digital conversion process. Encourage the development of interactive network television (IPTV), mobile TV, broadband cable network services, integration of services, driven by the chain enterprise collaborative development and improve the triple play technology innovation system. Governments at all levels to develop smart city and the digital home as a starting point for information consumption, actively developing policies. New Situation triple play radio and television networks to provide development opportunities, is also facing a serious challenge.

\section{Network Television's Impact on Traditional TV under the Background of Triple Play}

With the development of Internet technology, as well as the opportunity to triple play, Internet TV (OTTTV), this emerging network television has more advantage of the spread, mainly in multi-screen interaction, customization, playback, and ultra-tiled area limiting aspects.

In the traditional television era, we see through the TV stations according to their content are arranged to push as "communicator" stations in accordance with their own arrangements to "recipients" timely transmission of information, the audience can not choose their own time and program content. Therefore, we must endure lengthy advertising time, we do not like to tolerate television programs. The TV network to accommodate almost all the popular TV shows and a variety of non-mainstream programs, it offers the audience a variety of media television, Internet, cinema and other broadcast content, the audience can follow their own preferences, set in the mass customization of content their own program schedules and program component table.

As the latest form of network television in the background of the rise of triple play, Internet TV (OTTTV) not only inherited the online video "tiled" playback features, while both the applicability of the traditional family television, whereby it can be said, taking into account the advantages of network TV online video with traditional TV. 


\section{Television Network Development Strategy}

Multimedia technology to build a set of text, sound, images, video, communications and many other technology campus radio and television system in one, using digital recording and transmission of computer transmission method for processing a variety of media, with a wide range of uses, even replace the current variety of household appliances, computer sets, television sets, tape recorders, video recorders, VCD DVD machines, telephones, fax machines and other electrical appliances for one. Multimedia technology is involved in a very wide integrated technology, is open and no final boundaries of technology. Multimedia technologies related to computer hardware, computer software, computer networks, artificial intelligence, such as electronic publishing, the industry involved in the electronics industry, computer industry, radio, television, publishing and communications industries. Campus radio and television system is an important area of application of multimedia technology, and now some of the key schools and model schools have established a comprehensive campus television system, features a colorful, dazzling, but the establishment of such a system is costly, is not an ordinary school can affordable. However, in practical application, those powerful features is often little need them, in case of failure and difficult to solve, it will affect the teacher's teaching has caused a waste of money. I'm in school, for example, and we exchange some of our methods and skills in the transformation of campus radio and television system, there may be a lot less, hope colleagues to speak up.

Now the school campus broadcast television system application: receiving satellite TV, broadcast live, interactive intercom, shunt DVD media broadcast, videotape broadcast shunt and so on. However, with the decline in wide application of computer and network technology, hardware costs, such as shunt DVD media coverage can be replaced by a computer CD-ROM drive, and a lot of tape resources are also different levels of digitization, placed on the network, which is more It is a new trend. The interactive intercom function in this environment also lost useless. Essentially we use only the most satellite TV and feature a live broadcast. To this end, we re-locate, not seeking the best, just enough. In line with this principle, we have developed the following programs: a backbone network is still use the existing coaxial cable coaxial cable having a cheaper, more convenient laying advantage, therefore, generally small-scale video transmission process, because close distance, using a coaxial cable to transmit video images directly on the image quality is not damage that can meet the actual requirements. Generally speaking, the higher the frequency, the greater the attenuation. Bandwidth video signal is large, $6 \mathrm{MHz}$, and, and the color portion of the image is modulated at a higher frequency, so that the video signal is a coaxial cable the overall amplitude of the signal only when the transmission is attenuated, and the attenuation amount of the frequency components vary widely, in particular, the maximum attenuation of the color portion. Therefore, the coaxial cable is only suitable for short distance transmission image signal, when the transmission distance of 200 the right, the image quality will be significantly decreased, especially the color becomes dull and there is a sense of distortion. For a school, the parameters of this technology have been able to meet the actual demand. Coaxial amplifier amplifying a video signal having a certain, and also by a balanced adjustment of the different frequency components of different sizes are compensated for, so that the receiving end of the output video signal distortion as small as possible.

These standards and requirements at the school had already reached, so we are still the backbone network using existing coaxial cable. Second, to reduce the original DVD media coverage, the number of channels broadcast the tape because the previously mentioned before, the existing computer and network technology has been able to replace part of the DVD media broadcast, videotape broadcast functions (school classrooms are equipped with multimedia computers, and positive projector) so in the practical application of the original 16 in the passage to passage 8 (campus radio, live broadcast master control room, lecture hall live broadcast, satellite TV 3 sets of programs, DVD media broadcast a video tape broadcast each). Related to the equipment: satellite ground receiving antennas (commonly known as pot) tuner :( simple talk is accepted and a high-frequency signal amplifier tuned television signal) digital set-top boxes (satellite LNB LNB 
output signals into audio electronics video signals or radio frequency signals.) modulators television :( audio and video signal is modulated onto the band needed input for the audio-video signal, the output signal for a specific frequency band.) multi-channel mixer (the transmission) terminals multiplexed signals are mixed into one signal after use "audio and video modem" (commonly known as TV boxes) in practical applications, satellite ground receiving antenna, tuner, digital set-top boxes, multi-channel mixer all use the original there are devices, saving a lot of money, since the original TV modulator aging, and the offset frequency can not be adjusted, we have chosen to re-purchase, but the number has been effectively streamlined. Each classroom terminals used in audio and video modem was replaced, in order to improve television ratings. It is worth mentioning is that we will install a special position modulator such as lecture halls, sports hall, etc. (with the proviso that coaxial cable line has been laid) audio and video signal is then transmitted through the coaxial cable to the television center campus, connecting to the mixer input port, each terminal can receive the lecture hall, sports hall and other places live broadcast signal. We engineered this multimedia video systems may not be very professional, but she is very practical, for an ordinary school concerned enough, I hope in the near future, we want to be able to use the results of school or campus television system some learn things, to avoid detours, thereby saving costs, produce the greatest benefits.

Actively promote the next generation of broadcast television network construction, to meet the market demand for network infrastructure. Radio and television networks objective is to establish a "next generation" cable network, namely the construction can carry digital TV includes a variety of services, including two-way cable television network. Through the network bidirectional transformation, so that the cable television network to provide a variety of two-way data services, video, voice and broadband data to cable subscribers, realize a variety of business integration, namely the triple play, converting ordinary TV receiver into a home multimedia information terminals. At the same time continue to improve the structure of CATV trunk network, local conditions to expand the coverage of optical fiber transmission, and continuously improve the carrying capacity of cable television networks.

Always accompanied by the development of radio and television networks are constantly improving product innovation, product features, we will be better cost-effective products available to users to meet the information needs of users. Innovation can enhance the core competitiveness of enterprises. For example, the famous apple schools through innovation to market IPHONE and IPHONE-based OS mobile operating system, mobile phone hardware and improve, to develop better performance of mobile phones, and mobile phone operating system, but also continue to improve innovation through products continues upgrading to meet the needs of users, the school also achieved great success. Similarly, the school radio and television networks from analog to digital is complete revolution of innovation, developed in line with market demand for interactive TV product innovation is through innovation, radio and television networks to improve the competitiveness of the market.

\section{Conclusion}

In the gradually accelerating pace of triple play in the background, while the impact of network television and opportunities, the traditional television aspect should be strengthened on the basis of their own advantages, through the build quality television programs, strengthen the media business, to strengthen the promotion of digital TV and other ways to improve market competitiveness; on the other hand, we must also strengthen with the network television, to realize mutual benefits of both sides.

\section{References}

[1] John Steen. Actor-network theory and the dilemma of the resource concept in strategic management[J]. Scandinavian Journal of Management. 2010, (3)

[2] Jock Given. Take your partners: Public private interplay in Australian and New Zealand plans 
for next generation broadband [J]. Tele-communications Policy. 2010, (9)

[3] David Lewin, Brian Williamson, Martin Cave. Regulating next-generation fixed access to telecommunications services [J]. 2009, (4)

[4] Yoonhyuk Jung, Hyunmee Kang. User goals in social virtual worlds: A means-end chain approach [J]. Computers in Human Behavior. 2009, (2)

[5] Paul R. Messinger, Eleni Stroulia, Kelly Lyons, Michael Bone, Run H. Niu, Kristen Smirnov, Stephen Perelgut. Virtual worlds - past, present, and future: New directions in social computing [J]. Decision Support Systems. 2009, (3) 